\title{
Development of a Non-protein and Lipid Medium Adopted Cell Line for Biopharmaceutical Recombinant Protein Expression
}

\author{
Tetsuji Sasaki ${ }^{1,2,3}$ and Akiyoshi Taniguchi ${ }^{1,2, *}$ \\ ${ }^{I}$ Cell-Materials Interaction Group, Biomaterials Unit, International Center for Materials Nanoarchitectonics, National \\ Institute for Materials Science, 1-1 Namiki, Tsukuba, Ibaraki 305-0044, Japan \\ ${ }^{2}$ Biomaterials and Tissue Engineering, Graduate School of Comprehensive Human Science, University of Tsukuba, Tsu- \\ kuba, Ibaraki 305-8572, Japan \\ ${ }^{3}$ Kyokuto Pharmaceutical Industrial Co., Ltd. 3333-26 Aza-Asayama, Kamitezuna, Takahagi-shi, Ibaraki 318-0004, \\ Japan
}

\begin{abstract}
Recently, many biopharmaceuticals have been developed such as cytokines, growth factors, and antibodies. These recombinant proteins are mostly expressed by $\mathrm{CHO}$ cells. However, the culture medium of $\mathrm{CHO}$ cells requires the addition of serum, which can contain unknown biological substances such as viruses, or requires the addition of expensive growth factors. To avoid the risks of biological ingredients and to decrease the cost of biopharmaceutical production, we developed a non-protein and lipid medium adopted (NPLAd) CHO cell line using the adapted culture method. Our results indicated that autocrine EGF production and insulin addition are essential for NPLAd CHO cell growth. However, the rate of cell proliferation of NPLAd CHO cells was decreased compared with original CHO-K1 cells. The proliferation of NPLAd CHO cells was improved by GM3 addition, suggesting increased signaling efficiency of autocrine factors. No difference was found in the growth rate between original CHO-K1 and NPLAd CHO cells supplemented with insulin and GM3. The productivity of recombinant protein in NPLAd CHO cells was verified using secreting luciferase reporter system. As a result, luciferase activity in NPLAd CHO cells showed more than three times higher than in the original CHOK1 cells. The results suggested that this cell line could be useful for biopharmaceutical recombinant protein.
\end{abstract}

Keywords: Adapted culture method, biopharmaceutical, CHO cells, EGF, GM3, serum-free.

\section{INTRODUCTION}

The market share of biopharmaceuticals has been increasing in medicine [1,2]. Usually, biopharmaceuticals, which are recombinant proteins such as antibodies, hormones, or growth factors, are expressed using Escherichia coli, yeast, fungi, insect cells, or mammalian cells. Many recombinant proteins are expressed in E. coli because of rapid proliferation and/or the low cost of mass production cultures. However, the expression systems of E. coli and other microorganisms face many problems in the manufacture of biopharmaceuticals. For example, proteins cannot be fully post-translationally modified, such as by glycosylation. For some biopharmaceuticals, these modifications are important for their function, so proteins modified by glycosylation in E. coli expression systems have been studied [3]. However, these systems are not fully adequate. Therefore, many biopharmaceuticals are expressed using Chinese Hamster Ovary (CHO) cells [4].

*Address correspondence to this author at the 1-1 Namiki, Tsukuba, Ibaraki 305-0044, Japan/Cell-Materials Interaction Group, Biomaterials Unit, International Center for Materials Nanoarchitectonics, National Institute for Materials Science, Tsukuba, Ibaraki 305-8572, Japan/Biomaterials and Tissue Engineering, Graduate School of Comprehensive Human Science, University of Tsukuba; Tel:+81-29-860-4505; Fax: +81-29-860-4708;

E-mail: taniguchi.akiyoshi@nims.go.jp
Due to safety concerns in clinical use, the expression system of $\mathrm{CHO}$ cells should lack biological ingredients such as serum [5-8]. Biological ingredients increase the risk of infection by viruses of animal origin. Some growth factors have been used instead of serum for the proliferation of $\mathrm{CHO}$ cells; however, these growth factors are expensive and unstable [9]. To solve this problem, cell culture media should be of simple composition without the use of ingredients of biological origin and growth factors.

The adapted culture method is a good strategy to simplify $\mathrm{CHO}$ cell culture medium. However, in biological ingredient-free culture systems, the rate of cell proliferation is decreased. Proliferation in simplified cell culture medium often requires autocrine factors such as EGF [10]. To increase proliferation, the signaling efficiency of these autocrine factors should be increased.

In this study, we developed a non-protein and lipid medium adopted (NPLAd) cell line for biopharmaceutical recombinant protein expression. The proliferation rate of $\mathrm{CHO}$ cells in simplified culture medium was improved by insulin and GM3 addition. Our results suggest that this cell line could be useful for biopharmaceutical recombinant protein expression. 


\section{MATERIALS AND METHODS}

\section{Establishment of Adapted Cell Line}

Original CHO-K1 cell lines were obtained from the European Collection of Cell Cultures (from DS Pharma Biomedical Co., Ltd. import agency in Japan) and grown in monolayers in culture flasks. Cells were maintained in Dulbecco's minimum essential medium (DMEM, Kyokuto Pharmaceutical Industry, Japan) supplemented with 10\% Fetal Calf Serum (FCS, Life Technologies Corporation. California, USA). NPLAd CHO cells were propagated in a chemically defined low protein synthetic NPL medium (see Table 1). The cells were incubated at $37{ }^{\circ} \mathrm{C}$ in stationary cultures and the medium was renewed once a week. The morphology of the cells was observed by phase-contrast microscopy, and pictures were taken of specimens (DP12, Olympus, Tokyo, Japan).

Table 1. Components of NPL Medium

\begin{tabular}{|c|c|}
\hline Component & Concetration $(\mathrm{mg} / \mathrm{L})$ \\
\hline $\mathrm{NaCl}$ & 6,400 \\
\hline $\mathrm{KCl}$ & 400 \\
\hline $\mathrm{CaCl}_{2}$ (anhyd.) & 200 \\
\hline $\mathrm{MgSO}_{4}$ (anhyd.) & 98 \\
\hline $\mathrm{NaH}_{2} \mathrm{PO}_{4}$ (anhyd.) & 109 \\
\hline $\mathrm{Fe}\left(\mathrm{NO}_{3}\right)_{3} \cdot 9 \mathrm{H}_{2} \mathrm{O}$ & 0.2 \\
\hline $\mathrm{ZnSO}_{4} \cdot 7 \mathrm{H}_{2} \mathrm{O}$ & 2.0 \\
\hline $\mathrm{Na}_{2} \mathrm{SeO}_{3}$ & 0.0043 \\
\hline $\mathrm{CuSO}_{4} \cdot 5 \mathrm{H}_{2} \mathrm{O}$ & 0.002 \\
\hline HEPES & 4,000 \\
\hline Glucose (anhyd.) & 4,000 \\
\hline Sodium Pyruvate & 110 \\
\hline Phenol Red & 15 \\
\hline L-Alanine & 10 \\
\hline L-Arginine $\cdot \mathrm{HCl}$ & 164 \\
\hline L-Aspragine $\cdot \mathrm{H}_{2} \mathrm{O}$ & 50 \\
\hline L-Aspartic Acid & 25 \\
\hline L-Cystein $\mathrm{HCl} \cdot \mathrm{H}_{2} \mathrm{O}$ & 20 \\
\hline L-Cystine $\cdot 2 \mathrm{HCl}$ & 63 \\
\hline L-Glutamic Acid & 200 \\
\hline L-Glutamine & 584 \\
\hline Glycine & 30 \\
\hline L-Histidine $\mathrm{HCl} \cdot \mathrm{H}_{2} \mathrm{O}$ & 42 \\
\hline L-Isoleucine & 105 \\
\hline L-Leucine & 105 \\
\hline L-Lysine $\cdot \mathrm{HCl}$ & 146 \\
\hline
\end{tabular}

Table 1 Contd.....

\begin{tabular}{|l|r|}
\hline \multicolumn{1}{|c|}{ Component } & Concetration (mg/L) \\
\hline \hline L-Methionine & 30 \\
\hline L-Phenylalanine & 66 \\
\hline L-Proline & 100 \\
\hline L-Serine & 42 \\
\hline L-Threonine & 95 \\
\hline L-Tryptophan & 16 \\
\hline L-Tyrosine $\cdot \mathrm{HCl}$ & 72 \\
\hline L-Valine & 94 \\
\hline Biotin & 0.01 \\
\hline D-Ca Pantothenate & 4.0 \\
\hline Choline Chloride & 4.0 \\
\hline Vitamin B12 & 0.1 \\
\hline Folic Acid & 4.0 \\
\hline myo-Inositol & 4.53 \\
\hline Niacineamide & 0.2 \\
\hline Pyridoxal HCl & 0.7 \\
\hline Riboflavin & 7.2 \\
\hline Thiamine HCl & 4.0 \\
\hline Putrescine 2HCl & 4.0 \\
\hline Thymidine & 0.0 \\
\hline Hypoxanthine Na & 4.0 \\
\hline Monoethanolamine & 9.2 \\
\hline
\end{tabular}

\section{Cell Attachment Assay}

Cell attachment assays were performed using a commercially available fibronectin or type I collagen coated culture plates (Becton, Dickinson and Company, NJ, USA, respectively) and uncoated culture plates (Becton, Dickinson and Company). Albumin coated dishes were poured with $1 \mathrm{~mL}$ of $1 \mathrm{mg} / \mathrm{mL}$ BSA in PBS into the wells of non coated culture plates, and the plates were then incubated at $37^{\circ} \mathrm{C}$ for $2 \mathrm{~h}$ for coating, after which the wells were washed twice with PBS. NPLAd CHO cells were seeded on extracellular matrix (ECM) coated wells or uncoated wells for 5 days at $37^{\circ} \mathrm{C}$. The morphology of the cells was observed by phase-contrast microscopy, and pictures were taken of the specimens.

\section{Effect of Anti-EGF Antibody on Insulin-dependent NPLAd CHO Cell Growth}

NPLAd CHO cells were seeded at a concentration of $5 \mathrm{x}$ $10^{4}$ cells/mL per well into 24 -well culture plates and cultured for 5 days. They were then treated with varying concentrations of insulin (Sigma-Aldrich Co. LLC., MO, USA) and with or without $5 \mathrm{mg} / \mathrm{mL}$ Anti-EGF mAb (R\&D Systems, Inc., MN, USA). The final concentrations of insulin used 
were $0,1,2,5$, and $10 \mathrm{mg} / \mathrm{L}$. After incubation, cell numbers were determined with a hemocytometer. The cell numbers presented represent the means of three replicate wells \pm SD.

\section{Effect of GM3 on NPLAd CHO Cell Proliferation}

NPLAd CHO cells were seeded at a concentration of $5 \mathrm{x}$ $10^{4} \mathrm{cell} / \mathrm{s} / \mathrm{mL}$ per well into 24 -well culture plates and cultured for 5 days. They were then treated with $10 \mathrm{mg} / \mathrm{L}$ insulin and varying concentrations of GM3 (Neu5A, Enzo Life Sciences, Inc., NY, USA). The final concentrations of GM3 used were $0,250,1250$, and $2500 \mathrm{ng} / \mathrm{ml}$. After incubation, cell numbers were determined with a hemocytometer. The cell numbers presented represent the means of three replicate wells \pm SD. Statistical analysis was done with Student's t-test.

\section{Comparison of the Proliferation Rates of Original CHO- K1 and NPLAd CHO Cells}

Proliferation assays were performed in 24-well tissue plates with an initial cell density of $5 \times 10^{4}$ cells $/ \mathrm{mL}$ per well. NPLAd CHO cells were seeded in triplicate with 10 $\mathrm{mg} / \mathrm{L}$ insulin and $1250 \mathrm{ng} / \mathrm{mL}$ GM3 in NPL medium. After incubation, cell numbers were determined with a hemocytometer. Original CHO-K1 cell lines were seeded in triplicate in DMEM medium with $10 \%$ FBS. Cells were harvested by trypsinization and counted with a hemocytometer.

\section{Comparison of the Recombinant Protein Expression Revels of Original CHO-K1 and NPLAd CHO Cells}

Recombinant protein expression assays were performed in 24-well tissue plates with an initial cell density of $4 \times 10^{5}$ cells $/ 0.5 \mathrm{~mL}$ per well. Original CHO-K1 cells were seeded in DMEM medium with $10 \%$ FCS and cultured for $24 \mathrm{~h}$. NPLAd CHO cells were seeded in NPL medium with 10 $\mathrm{mg} / \mathrm{L}$ of insulin and with or without $1250 \mathrm{ng} / \mathrm{mL}$ of GM3 and cultured for $24 \mathrm{~h}$. Transfection Complex was made in advance of transfection, adjusted by adding $50 \mu \mathrm{L}$ DMEM medium to $1.5 \mu \mathrm{L}$ Trans IT-LT1 Transfection Reagent (Mirus Bio LLC., Wisconsin, USA) and $0.5 \mu \mathrm{g} / 0.5 \mu \mathrm{L}$ NanoLuc reporter vector pNL1.3.CMV [secNluc/CMV] (Promega Corporation, Wisconsin, USA). For transfection, Transfection Complex was dropwised $52 \mu \mathrm{L} /$ well of incubated culture plates. After transfection, supernatants were fractionated at $5,24,48,72$ and $120 \mathrm{~h}$ to measure the secreted luciferase activity. We used the Nano-Glo Luciferase Assay System ${ }^{\mathrm{TM}}$ (Promega Corporation, Wisconsin, USA) for measurement of secreted luciferase activity. $45 \mu \mathrm{L}$ of DMEM medium and $25 \mu \mathrm{L}$ of Nano-Glo Luciferase substrate were added to $5 \mu \mathrm{L}$ of culture supernatants after transfection, and then, the mixtures were incubated at room temperature for $3 \mathrm{~min}$, and then, measured by the amount of light emitted by the luminometer (Lumat LB9507, BERTHOLD TECHNOLOGIES GmbH \& Co., Germany). Relative luciferase activity (\%) was calculated by dividing luminescence using Original CHO-K1 cells to luminescence using NPLAd CHO cells or GM3 added NPLAd CHO cells. Relative luciferase activities were indicated by the means of three individual replicate $\pm \mathrm{SD}$. Statistical analysis was done with Student's t-test.

\section{RESULTS}

\section{Establishment of NPLAd Cell Line}

We developed the NPLAd cell line by the adapted culture method. In general, $\mathrm{CHO}$ cells are cultured using medium containing $10 \%$ serum. Using the adapted culture method, cells were cultured in gradually reduced serum concentrations until cells could be grown in basal medium lacking serum and growth factors.

Completely eliminating the serum was possible by reducing the concentration over 3 months. In low serum concentrations, such as $1 \%$, $\mathrm{CHO}$ cells begin to float and detach from the flask vessel wall. When the serum was completely removed from the medium, most $\mathrm{CHO}$ cells changed to a floating state.

Fig. (1) shows the morphology of the established CHO cell line (NPLAd CHO cells; A) and original CHO-K1 cell line (B). The original CHO-K1 cells adhered to the bottom of flasks with a cobblestone like form. However, NPLAd $\mathrm{CHO}$ cells were non-adherent, and the cell size was much larger. In the production of biopharmaceuticals, CHO cells are cultured in suspension in tanks using detergents, such as Tween-80 or Pluronic F68 [11]. These detergents are toxic to the cells and are time-consuming to remove from purified biopharmaceutical products. This result suggests that the NPLAd CHO cells can easily and safely be cultured in suspension without detergents.

\section{Attachment to Protein-coated Culture Dishes}

In order to identify if the floating form of NPLAd CHO cells occurs due to a deficiency in cell adhesion factors from the lack of serum, we cultured them in plates coated with various proteins or ECM, which were fibronectin, collagen, and albumin. As shown in Fig. (2), NPLAd CHO cells did not adhere to fibronectin, collagen, or albumin coated dishes. The results indicated that the floating potential of NPLAd CHO cells was not affected by ECM or protein coating of dishes.
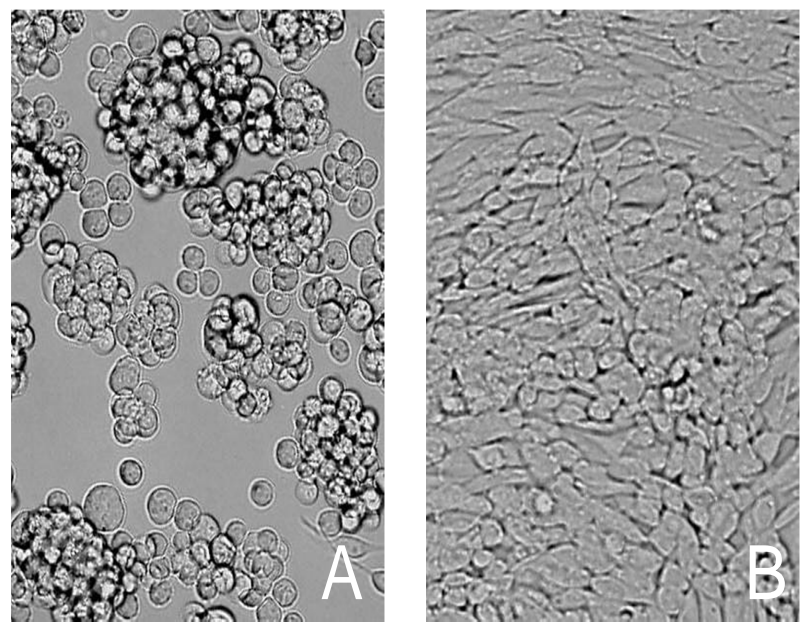

Fig. (1). Morphology of the established CHO cell line (NPLAd $\mathrm{CHO}$ cells; A) and original CHO-K1 cell line (B). The magnification is $100 \mathrm{x}$. 

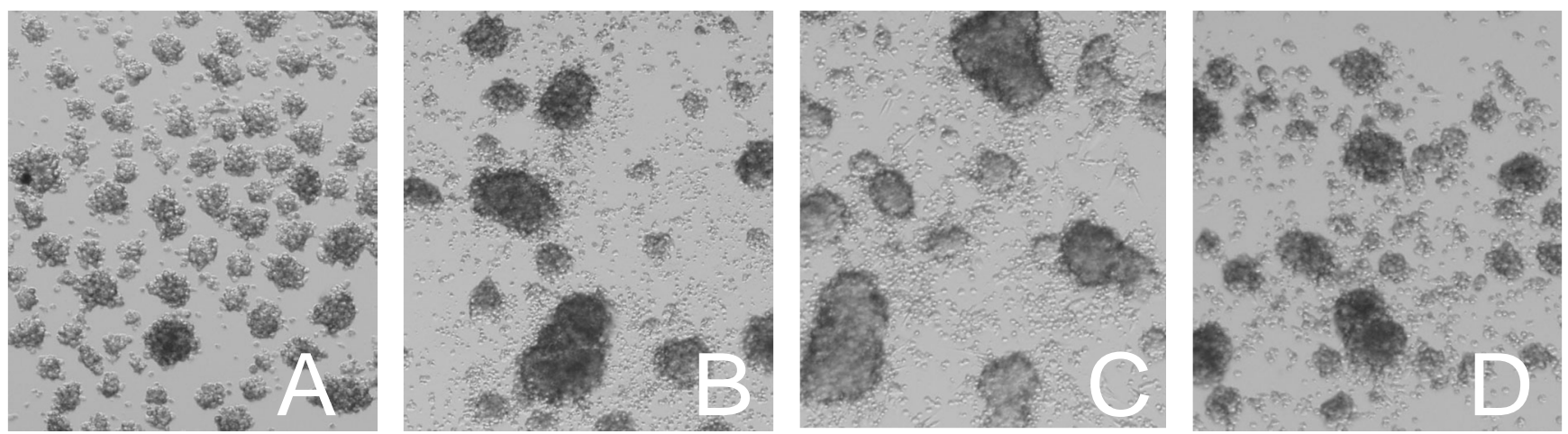

Fig. (2). Effects of extracellular matrix coatings on the attachment and morphology of NPLAd CHO cells. A: Non-coated dish; B: Fibronectin-coated dish; C: Collagen-coated dish; D: albumin-coated dish. The magnification is 40x.

\section{Effect of Anti-EGF Antibody on Insulin-dependent NPLAd CHO Cell Growth}

Insulin is an essential growth factor for many cell lines, so we investigated the effect of insulin concentrations on the growth rate of NPLAd CHO cells. As a result, insulin addition increased the growth rate of NPLAd CHO cells in a dose-dependent manner (Fig. 3, closed circles).

The cell proliferation rate is an important factor for industrial applications. As NPLAd CHO cells were prepared by adapted culture of serum-free basal medium, the cell proliferation rate of NPLAd CHO cells was significantly slower than the original $\mathrm{CHO}$ cells. In general, the growth of $\mathrm{CHO}$ cells is maintained by growth factors contained in the serum, and the NPL medium contains no serum or growth factors. Therefore, we hypothesized that NPLAd CHO cells grew using autocrine growth factors such as EGF. We examined the effect of EGF on cell proliferation by blocking it with an anti-EGF antibody. Furthermore, we investigated the effect of anti-EGF antibody on insulin-induced cell proliferation.

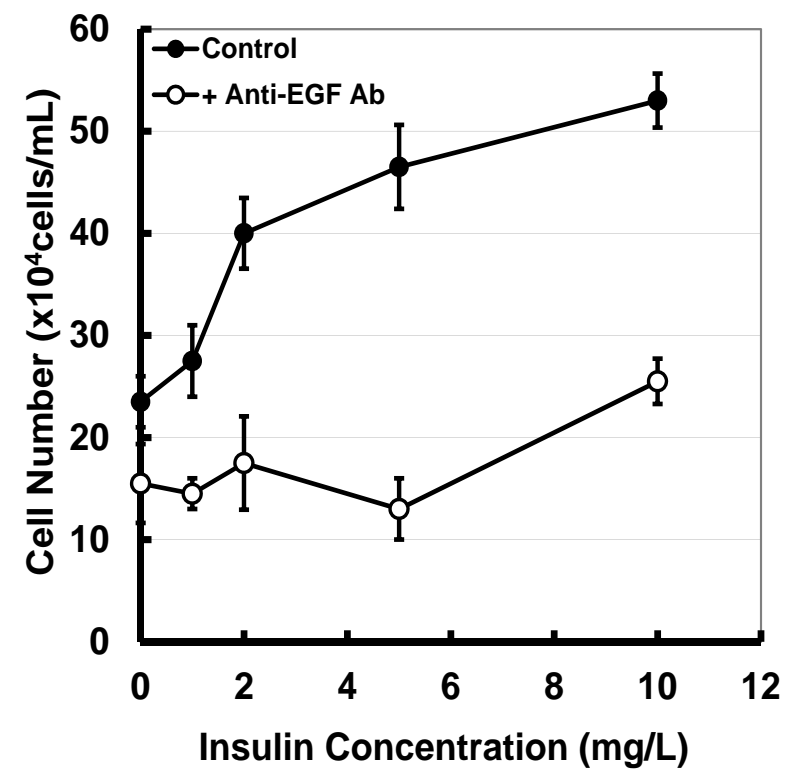

Fig. (3). Effect of anti-EGF antibody on insulin-dependent NPLAd $\mathrm{CHO}$ cell growth. The insulin dose-dependence of NPLAd CHO cell growth with or without $5 \mathrm{mg} / \mathrm{ml}$ of anti-EGF antibody is shown as open or closed circles, respectively.
As a result, the addition of $5 \mathrm{mg} / \mathrm{mL}$ anti-EGF antibody inhibited insulin-dependent NPLAd CHO cell growth (Fig. 3 open circles). The results suggest that autocrine EGF production is essential for NPLAd CHO cell growth.

\section{Effect of GM3 on NPLAd CHO Cells Proliferation}

Our results indicated that the insulin-induced proliferation of NPLAd CHO cells was inferior to the serum-induced proliferation of original CHO cells. NPL medium does not contain any lipid components. One possible explanation for the low proliferation of NPLAd CHO cells is that they lack enough lipids for raft formation. Lipid rafts, a kind of membrane microdomain, is an area on the cell membrane rich in gangliosides, cholesterol, and sphingolipids. This structure is a functional domain having an important role in signal transduction through the cell membrane [12-14]. GM3 ganglioside is an important component of lipid raft formation $[15,16]$, so we therefore tested the effect of GM3 on NPLAd $\mathrm{CHO}$ cell proliferation. As shown in Fig. (4), the addition of GM3 at a concentration of more than $1250 \mathrm{ng} / \mathrm{mL}$ increased

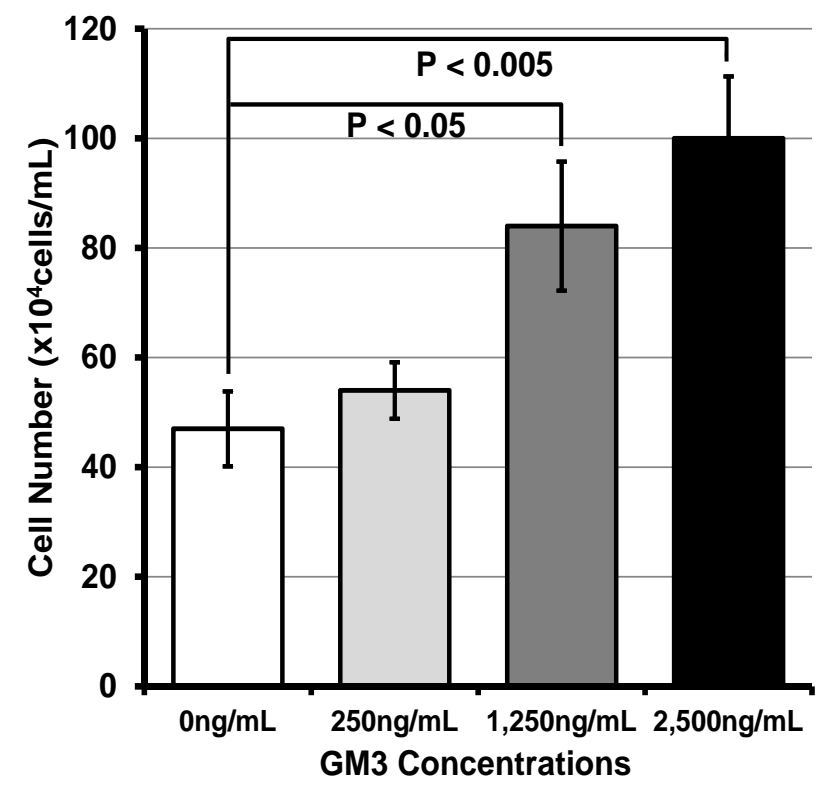

Fig. (4). Effect of GM3 on NPLAd CHO cell proliferation. NPLAd $\mathrm{CHO}$ cells were cultured with varying GM3 concentrations. After 5 days, cell numbers were counted. 
the cell numbers significantly. The results indicated that NPLAd CHO cells were able to increase growth rate by the addition of GM3 to NPL medium.

\section{Comparison of the Proliferation Rate of Original CHO-K1 and NPLAd CHO Cells}

We compared the growth rate of NPLAd CHO cells and original $\mathrm{CHO}$ cells, which were cultured by the addition of $10 \%$ serum. As shown in Fig. (5), no difference was found in the growth rate between original CHO-K1 and NPLAd CHO cells. This result indicates that the addition of GM3 improved the growth rate of NPLAd CHO cells to that of the original cells.

\section{Comparison of the Recombinant Protein Expression of Original CHO-K1 and NPLAd CHO Cells}

The productivity of recombinant protein in NPLAd CHO cells was verified using secreting luciferase reporter system. Plasmids containing secreted luciferase gene were transfected into original CHO-K1 cells and NPLAd CHO cells with or without GM3 $(1250 \mathrm{ng} / \mathrm{mL})$. The luciferase activity of GM3 added NPLAd CHO cells was similar to the original CHO-K1 cells after 120 hours post-transfection (Fig. 6, black circles). The luciferase activity of NPLAd CHO cells without GM3 showed more than three times higher than the that of original CHO-K1 cells after 120 hours posttransfection (Fig. 6, open circles). Growth rate of NPLAd $\mathrm{CHO}$ cells without GM3 was slower than that of original $\mathrm{CHO}$ cells. The per cell luciferase activity of established cells showed more than four times higher than the that of original CHO-K1 cells (data not shown). The results suggested that the productivity of recombinant protein in NPLAd CHO cells was higher than original CHO-K1 cells.

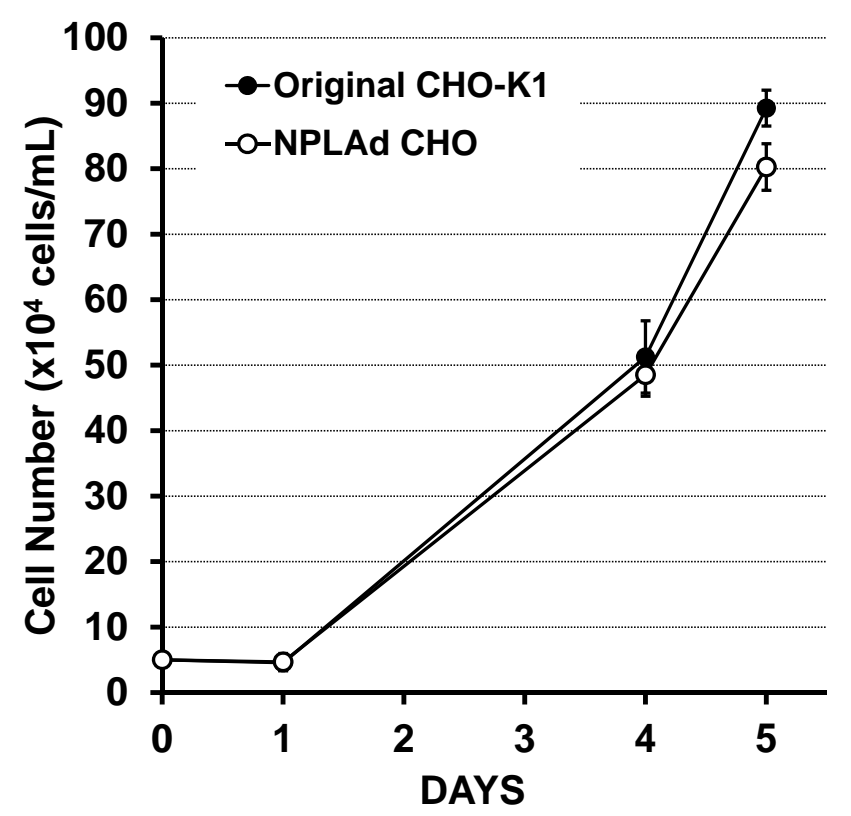

Fig. (5). Comparison of the proliferation rate of original CHO-K1 (open circles) and NPLAd CHO cells (closed circles). The original CHO-K1 cells were cultured with DMEM containing 10\% FBS. NPLAd CHO cells were cultured with NPL medium containing 10 $\mathrm{mg} / \mathrm{L}$ of insulin and $1250 \mathrm{ng} / \mathrm{mL}$ of GM3.

\section{DISCUSSION}

The culture of $\mathrm{CHO}$ cells requires biological ingredients $[17,18]$, which are not guaranteed to biological safe, or requires the addition of expensive growth factors $[19,20]$. To solve these problems, we established NPLAd CHO cells using the adapted culture method.

Our results indicated that cell growth of NPLAd CHO cells was increased by the addition of insulin in a dosedependent manner. Original $\mathrm{CHO}$ cells also need insulin in serum-free medium, along with other growth factors [20], for cell growth. These results suggest that the addition of insulin to medium is essential for cell growth in $\mathrm{CHO}$ cells.

The NPL medium does not contain any serum or growth factors. Therefore, we hypothesized that NPLAd CHO cells grew due to autocrine growth factors such as EGF, which is known to act as an autocrine growth factor in some cell lines $[10,21,22]$. In our results, the cell proliferation of NPLAd $\mathrm{CHO}$ cells was inhibited by using a neutralizing antibody to block EGF (Fig. 3), suggesting that cell growth required autocrine production of EGF.

The NPLAd CHO cell growth rate was equivalent to that of the original $\mathrm{CHO}$ cells, which were cultured in serumsupplemented medium, by the addition of GM3. Gangliosides are present in the lipid rafts on the surfaces of cell membranes, and some gangliosides regulate signal transduction $[12-14,23]$. NPL medium does not contain any lipid components (see Table 1), including glycolipids such as gangliosides. These lipid components can be made by selfbiosynthesis [24]; however, in many cases, the lipid compo-

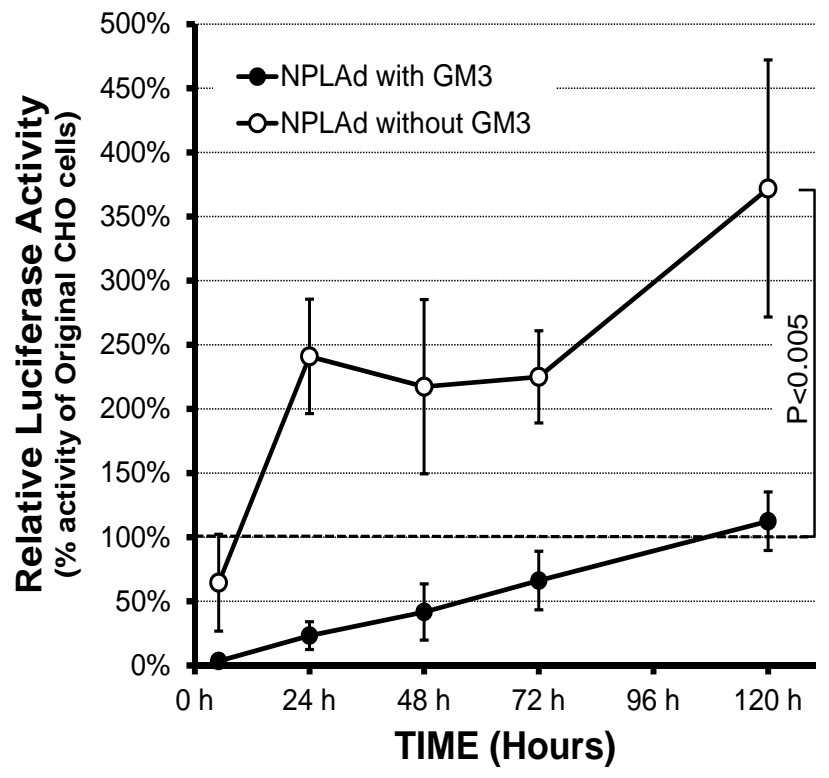

Fig. (6). Comparison of the recombinant protein expression levels of original CHO-K1 and NPLAd CHO cells with or without GM3 using secreting luciferase reporter system. The plasmid containing secreted luciferase gene was transfected into original CHO-K1 and NPLAd CHO cells, luciferase activities in cultured medium of transfected cells were measured at each time period. Relative luciferase activity (\%) was calculated by dividing luminescence activity of original $\mathrm{CHO}-\mathrm{K} 1$ cells to luminescence activity of NPLAd CHO with (closed circles) or without GM3 (open circles). 
nents must be supplied from biological materials such as serum [25]. We hypothesized that NPLAd CHO cells had low proliferation because they lacked enough lipids for raft formation. Our results suggest that autocrine signaling transduction is improved by the addition of GM3. Furthermore, the productivity of recombinant protein in NPLAd CHO cells was higher than original CHO-K1 cells.

In conclusion, we established a suspension NPLAd CHO cell line by adaptation to NPL medium. This cell line could be useful for the high production of biopharmaceutical proteins and growth equivalent to that of original $\mathrm{CHO}$ cells.

\section{ACKNOWLEDGEMENT}

None declared.

\section{CONFLICT OF INTEREST}

The authors confirm that this article content has no conflicts of interest.

\section{REFERENCES}

[1] Obradovic M, Mrhar A, Kos M. Market uptake of biologic and small-molecule-targeted oncology drugs in Europe. Clin Ther 2009; 31: 2940-52.

[2] Krishan M. Monoclonal Antibody "Gold Rush". Curr Med Chem 2007; 14: 1978-87.

[3] Pandhal J, Desai P, Walpole C, Doroudi L, Malyshev D, Wright PC. Systematic metabolic engineering for improvement of glycosylation efficiency in Escherichia coli. Biochem Biophys Res Commun 2012; 419: 472-6.

[4] Kelley B. Industrialization of mAb production technology: the bioprocessing industry at a crossroads. MAbs 2009; 1: 443-52.

[5] Kurano S, Kurano N, Leist C, Fiechter A. Utilization and stability of vitamins in serum-containing and serum-freemedia in $\mathrm{CHO}$ cell culture. Cytotechnology 1990; 4: 243-50.

[6] Hata J, Tamura T, Yokoshima S, et al. Chemically defined medium for the production of biologically active substances of $\mathrm{CHO}$ cells. Cytotechnology 1992; 10: 9-14.

[7] Dyring C, Hansen HA, Emborg C. Observations on the influence of glutamine, asparagine and peptone on growth and t-PA production of Chinese hamster ovary (CHO) cells. Cytotechnology 1994; 16: $37-42$.

[8] Castro PM, Ison AP, Hayter PM, Bull AT. CHO cell growth and recombinant interferon-gamma production: Effects of BSA, Pluronic and lipids. Cytotechnology 1995; 19: 27-36.

[9] Sunstrom NA, Gay RD, Wong DC, Kitchen NA, DeBoer L, Gray PP. Insulin-Like Growth Factor-I and Transferrin Mediate Growth and Survival of Chinese Hamster Ovary Cells. Biotechnol Prog 2000; 16: 698-702.
[10] Fisher DA. Epidermal growth factor in the developing mammal. Mead Johnson Symp Perinat Dev Med 1988; (32): 33-40.

[11] Tharmalingam T, Ghebeh H, Wuerz T, Butler M. Pluronic enhances the robustness and reduces the cell attachment of mammalian cells. Mol Biotechnol 2008; 39: 167-77.

[12] Sorice M, Longo A, Garofalo T, Mattei V, Misasi R, Pavan A. Role of GM3-enriched microdomains in signal transduction regulation in T lymphocytes. Glycoconj J 2004; 20: 63-70.

[13] Bremer EG, Hakomori S, Bowen-Pope DF, Raines E, Ross R. Ganglioside-mediated modulation of cell growth, growth factor binding, and receptor phosphorylation. J Biol Chem 1984; 259: 6818-25.

[14] Lopez PH, Schnaar RL. Gangliosides in cell recognition and membrane protein regulation. Curr Opin Struct Biol 2009; 19: 549-57.

[15] Garofalo T, Lenti L, Longo A, et al. Association of GM3 with Zap70 induced by $\mathrm{T}$ cell activation in plasma membrane microdomains: GM3 as a marker of microdomains in human lymphocytes. J Biol Chem 2002; 277: 11233-8.

[16] Merrill AH Jr. Sphingolipid and Glycosphingolipid Metabolic Pathways in the Era of Sphingolipidomics. Chem Rev 2011; 111 6387-422.

[17] Dyring C, Hansen HA, Emborg C. Observations on the influence of glutamine, asparagine and peptone on growth and t-PA production of Chinese hamster ovary (CHO) cells. Cytotechnology 1994; 16: 37-42.

[18] Jenkins N, Castro P, Menon S, Ison A, Bull A. Effect of lipid supplements on the production and glycosylation of recombinant interferon-gamma expressed in CHO. Cytotechnology 1994; 15: 20915.

[19] Hunt SM, Pak SC, Bridges MW, Gray PP, Sleigh MJ. Chinese hamster ovary cells produce sufficient recombinant insulin-like growth factor I to support growth in serum-free medium. Serumfree growth of IGF-I-producing CHO cells. Cytotechnology 1997; 24: 55-64.

[20] Chun C, Heineken K, Szeto D, Ryll T, Chamow S, Chung JD. Application of factorial design to accelerate identification of $\mathrm{CHO}$ growth factor requirements. Biotechnol Prog 2003; 19: 52-7.

[21] Shvartsman SY, Hagan MP, Yacoub A, Dent P, Wiley HS, Lauffenburger DA. Autocrine loops with positive feedback enable context-dependent cell signaling. Am J Physiol Cell Physiol 2002; 282: C545-59.

[22] DeWitt AE, Dong JY, Wiley HS, Lauffenburger DA. Quantitative analysis of the EGF receptor autocrine system reveals cryptic regulation of cell response by ligand capture. J Cell Sci 2001; 114: 2301-13.

[23] Kaucic K, Liu Y, Ladisch S. Modulation of Growth Factor Signaling by Gangliosides: Positive Or Negative? Methods Enzymol 2006; 417: 168-85.

[24] Fielding CJ, Fielding PE. Intracellular cholesterol transport. J Lipid Res 1997; 38: 1503-21.

[25] Mendez AJ, Lin G, Wade DP, Lawn RM, Oram JF. Membrane Lipid Domains Distinct from Cholesterol/Sphingomyelin-Rich Rafts Are Involved in the ABCA1-mediated Lipid Secretory Pathway. J Biol Chem 2001; 276: 3158-66. 